\title{
First highly stereocontrolled synthesis of tetrahydro trans- $\beta$-carboline derivatives by exploiting the influence of a cyclic amide
}

\author{
Ravindra Vedantham, ${ }^{\text {a,b }}$ Sakthivel Shanmugam, ${ }^{\text {a }}$ Prasadaraju VNKV Vetukuri, \\ Mukkanti Khagga ${ }^{b}$ and Rakeshwar Bandichhor*a \\ ${ }^{a}$ Research and Development, API, Integrated Product Development, Innovation Plaza, \\ Dr. Reddy's Laboratories Ltd, Bachupally, Qutubullapur, R.R. Dist-500072, A.P., India \\ ${ }^{b}$ Institute of Science and Technology, Jawaharlal Nehru Technological \\ University, Kukatpally, Hyderabad 500072, A.P., India \\ E-mail: rakeshwarb@drreddys.com
}

Dedicated to Professor Richard R. Schmidt on the occasion of his 78th anniversary

\begin{abstract}
Stereocontrolled synthesis of trans- $\beta$-carboline derivatives by employing amidation strategy is presented.
\end{abstract}

Keywords: Stereocontrolled, tryptophan, $\beta$-carboline, diketopiperazine, tadalafil, mixed anhydride

\section{Introduction}

Carbolines and tetrahydro- $\beta$-carbolines as shown in Figure 1 are the key building blocks of many drug candidates and are abundantly found in natural products. ${ }^{1}$ Considering their medicinal significance, many synthetic pathways have been developed. ${ }^{2}$ There are few functionalized tetrahydro- $\beta$-carboline derivatives that were identified as selective PDE5 inhibitors and antihypertensive agents. ${ }^{3}$ Of these, $(6 R, 12 \mathrm{a} R)-6$-(1,3-benzodioxol-5-yl)-2-methyl-1,2,3,4,6,7,12,12aoctahydropyrazino[1',2':1,6]pyrido[3,4-b]indole-1,4-dione, tadalafil (1c; Figure 1) is a potent orally active phosphodiesterase (PDE5) inhibitor ${ }^{3}$ discovered by GlaxoSmithKline, which is widely used for the management of erectile dysfunction (ED) under the trade names Cialis ${ }^{\circledR}$ and Adcirca ${ }^{\circledR}$.

The Pictet-Spengler reaction ${ }^{4}$ that involves the cyclization of relatively electron-rich aromatic framework by involving imine or iminium moieties is method of choice for constructing carbolines. ${ }^{5}$ This strategy has been employed in the total synthesis of numerous natural products 
including azatoxin, $1 \mathrm{a}^{6}$ and alstophylline $\mathbf{1 b} .^{7,8}$ Additionally, tetrahydro- $\beta$-carboline-hydantoin and tetrahydro- $\beta$-carboline piperazinedione scaffolds were also identified to have anti-cancer ${ }^{9}$ and anti-HIV activities. ${ }^{10}$
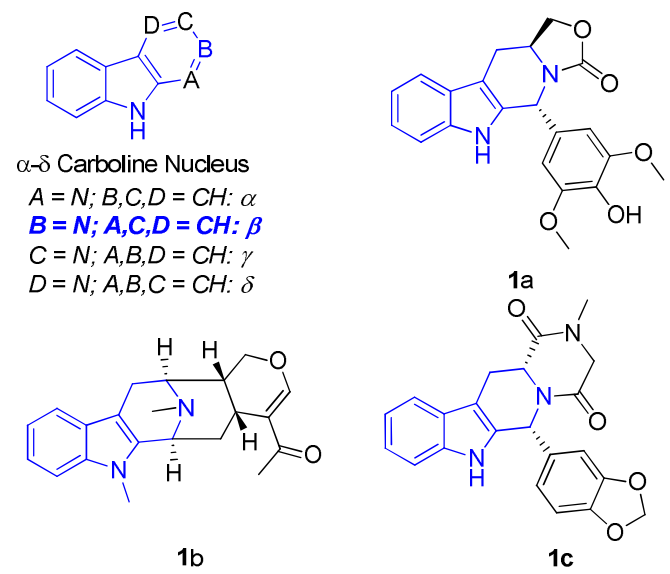

Figure 1. Core structure of carbolines and medicinally relevant entities.

We were interested to work on tadlafil and its isomers and the literature search revealed that the first synthesis of tadalafil 1c was described by two groups Martin et al. ${ }^{11}$ and Daugan et al. ${ }^{12}$ Both the approaches involve cyclization of D-tryptophan methyl ester $\mathbf{3}$ with piperonal $\mathbf{2}$ using trifluoroacetic acid (TFA) in dichloromethane that afforded $(1 R, 3 R)$-cis-pyrido-indole derivative 4 via isomerization (cis/trans: from 60/40 to 97/03). Thereafter, acylation of 4 with chloroacetyl chloride $\mathbf{5}$ yielded the chloroacetyl derivative $\mathbf{8}$, which was finally subjected to cyclization with methylamine in methanol to yield 1c as shown in Scheme 1. Moreover, direct activation of tryptophan $\mathbf{6}$ with DCC/HOBt followed by reaction with 9 afforded tadalafil 1c.

Considering the presence of two chiral centres, most of the synthesis of 1c employed the commercially available D-tryptophan derivative that has predisposed systemic chirality, and the second chiral center was generated through substrate controlled Pictet-Spengler type cyclization followed by acid mediated transformation of the trans isomer to the desired cis isomer predominantly as shown in Figure $2 .{ }^{13}$ Unlike to amino ester, $\beta$-carboline trans $\mathbf{- 4}$, isomerization of trans-tadalafil 12 to tadalafil 1c was unsuccessfully attempted (Figure 2).

An alternative synthesis of 1c was reported ${ }^{14}$ starting from L-tryptophan in seven steps. Another approach employed sarcosine ester 9 through double amidation ${ }^{15}$ based two-step synthesis of 1c. Recently, Shi. et al. ${ }^{16}$ has published the synthesis of 1c using an improved acid catalyzed stereoselective Pictet-Spengler reaction. So far, to the best of our knowledge, apart from substrate controlled stereocontrolled synthesis disclosed by Cook et al., ${ }^{17}$ there is no methodology reported that describes the synthesis of exclusively trans- $\beta$-carboline derivatives by manipulating amide functionalty. Herein, we disclose a methodology that enabled us to 
synthesize trans- $\beta$-carboline derivative in a stereocontrolled manner using the diketopiperazine moiety present in the substrate.

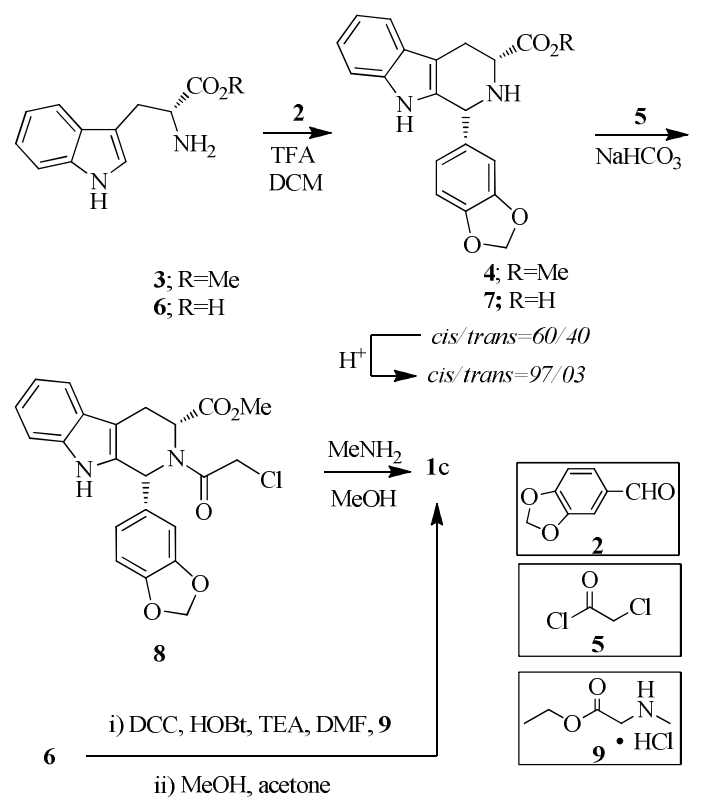

Scheme 1. Precedented approaches for tadalafil synthesis.
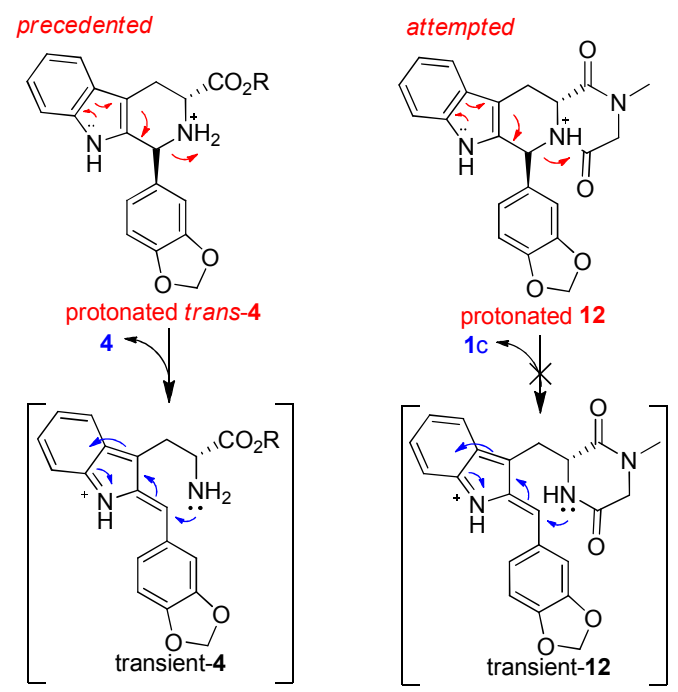

Figure 2. Acid mediated trans-cis isomerisation. 


\section{Results and Discussion}

In our endeavors, we attempted the synthesis of $\mathbf{1 c}$ and its isomer via new intermediates starting from the commercially available $N$-Boc-D-tryptophan 10. In this approach, mixed anhydride methodology was adopted for amidation using sarcosine moiety. Considering the thermodynamic stability of trans- $\beta$-carboline over its cis isomer as reported, ${ }^{9,16-19}$ we first explored the possibility of a stereocontrolled synthesis of the $S, R$ diastereomer of trans tadalafil 12.

As shown in Scheme 2, substrate 10 was treated with ethyl chloroformate (ECF) to generate its mixed anhydride in situ followed by reaction with 9 to yield an intermediate 11. Thereafter, at higher temperature, we were able to construct piperazine ring in a trans $(S, R)$ fashion yielding 12 while at lower temperature $R, R$ isomer, tadalafil 1c was observed. Predominant formation of 1c, at low temperature, is due to the fact that the slow reaction rate of piperazine ring construction led to an epimerization of the trans isomer to cis isomer $13^{13,16,20}$ followed by intramolecular amidation.

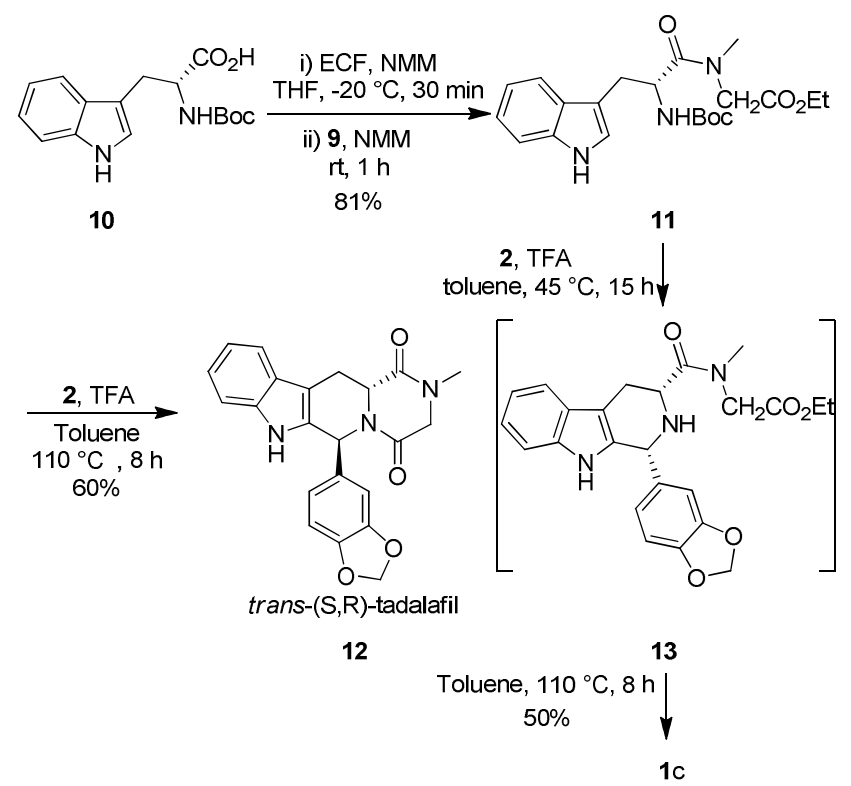

Scheme 2. New synthetic approach for tadalafil 1c and its trans isomer $\mathbf{1 2}$.

Secondly, we examined the transformation switch strategy where the piperazine ring was constructed first either starting from intermediate $\mathbf{1 1}$ or 3 to access $\mathbf{1 5}$. Thereafter, reaction of 15 with aldehyde $\mathbf{2}$ afforded stereocontrolled trans isomer $\mathbf{1 2}$ in excellent yield as shown in Scheme 3. 


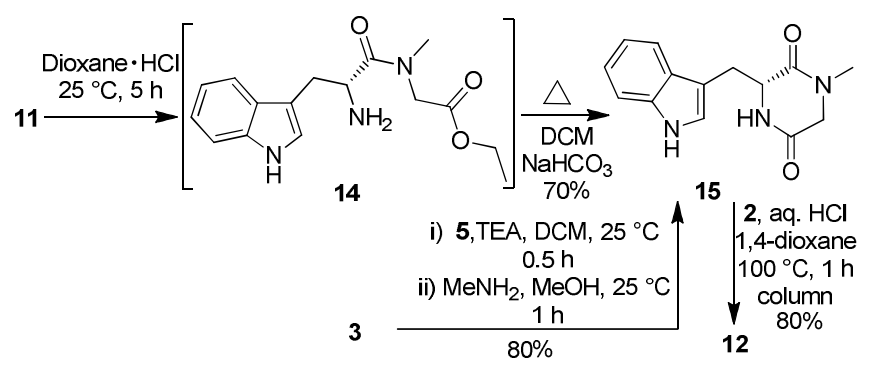

Scheme 3. Transformation switch strategy for trans tadalafil 12.

Encouraged by the outcome of Scheme 3, we intended to establish a generality of this approach by diversifying the intermediate $\mathbf{1 5}$ to synthesize few derivatives of trans tadalafil $\mathbf{1 2}$. Such an approach led to a new methodology (Schemes 3 and 4) for modified stereocontrolled Pictet-Spengler reaction to synthesize $\beta$-carboline derivatives starting from 1,4-diketopiperazine scaffold. This type of diketopiperazine derivatives e.g. $S$ isomer of $\mathbf{1 5}$ are recently disclosed in different context by using the Ugi reaction strategy. ${ }^{21}$ Hitherto known procedures for modified Pictet-Spengler reaction were found to utilize amines, substituted amines ${ }^{1,3,12,14,15,22}$ or carbamates $^{23}$ for $\beta$-carboline synthesis. However, in our approach, we utilized amide $\mathbf{1 5}$ to yield $\beta$-carboline derivatives $\mathbf{1 7} \mathrm{a}-\mathrm{c}$ and $\mathbf{1 2}$ as shown in Scheme 4.

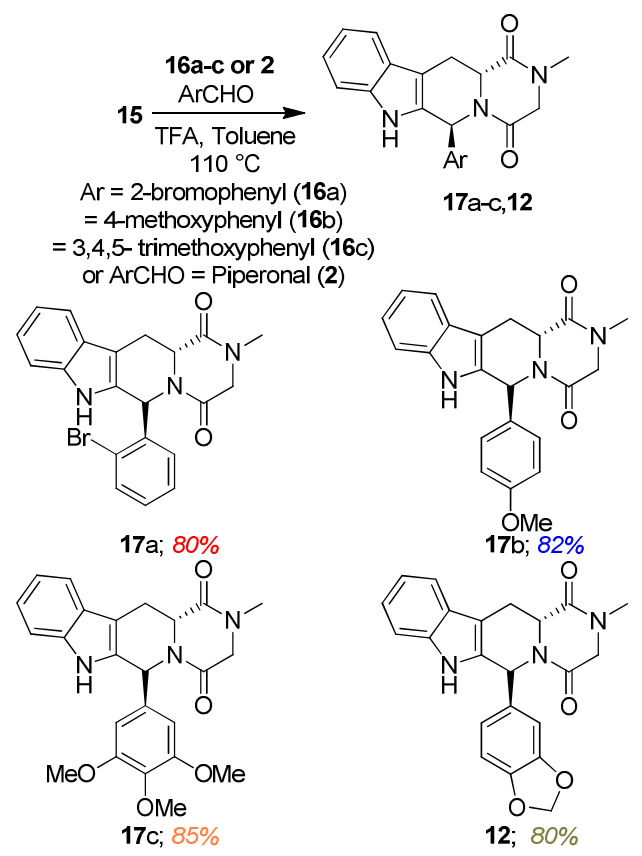

Scheme 4. Synthesis of congeners of trans tadalafil 12.

Isomerisation of $\beta$-carbolines ${ }^{9,19}$ are well documented and the literature findings reveal that the use of bulky moieties e.g. esters of tryptophan result in trans isomers predominantly at higher 
temperature however at lower temperature the cis isomer can preferably be obtained. , $17,19,20,22-23^{2}$ Considering the low reactivity than amines and structural attributes of amide, it is quite apparent that the intermediate $\mathbf{1 5}$ can offer conformationally locked six membered sterically constrained amide ring system which is amenable to afford trans products 17a-c including 12 plausibly due the iminium transition state where the carboline ring might form from top of the plane as depicted in the Figure 3.

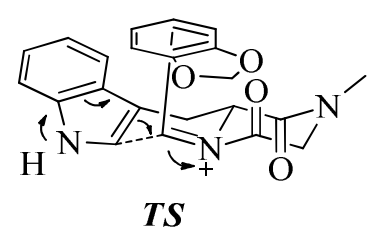

Figure 3. Transition state disposed for affording trans product.

We also observed the influence of acid and solvent in the condensation to obtain in situ iminium species followed by carboline ring formation. Aq. $\mathrm{HCl}$ in 1,4-dioxane was found to be suitable to affect the carboline ring formation at $100{ }^{\circ} \mathrm{C}$ in $95 \%$ conversion as shown in Table 1 (entry 2).

Table 1. Acid screening for $\beta$-carboline synthesis

\begin{tabular}{ccccc}
\hline Entry & Acid/solvent & $\begin{array}{c}\text { Temp } \\
\left({ }^{\circ} \mathrm{C}\right)\end{array}$ & $\begin{array}{c}\text { Time } \\
(\mathrm{h})\end{array}$ & $\begin{array}{c}\text { Trans } \\
(\%)\end{array}$ \\
\hline 1 & PTSA/toluene & 105 & $8^{*}$ & 70 \\
2 & aq. $\mathrm{HCl} /$ 1,4-dioxane & 100 & 7 & 95 \\
3 & aq. $\mathrm{HCl} /$ acetonitrile & 82 & 10 & 15 \\
4 & aq. $\mathrm{HCl} / 2$-propanol & 85 & 10 & 10 \\
5 & aq. $\mathrm{HCl} /$ ethanol & 78 & 10 & 10 \\
6 & aq. $\mathrm{HCl}$ & 100 & 10 & 10 \\
7 & $\mathrm{BF}_{3} /$ Ether & 25 & $5^{*}$ & - \\
\hline
\end{tabular}

*reaction did not proceed to completion.

\section{Conclusions}

In summary, we have successfully demonstrated an unprecedented stereocontrolled synthesis of trans isomer of tadalafil 12 and $\beta$-carboline derivatives 17a-c. The method disclosed here is the first of its kind for the synthesis of $\beta$-carbolines that employs the less reactive amide rather than the amine. 


\section{Experimental Section}

General. All starting materials were commercial substances. LR grade solvents and commercial reagents were used without further purification. The FT IR spectra were recorded as $\mathrm{KBr}$ pallet and only diagnostic and/or intense peaks are reported. Mass spectra $(70 \mathrm{eV})$ were recorded on LC-MS spectrometer. The melting points were determined by using the capillary method and are uncorrected. ${ }^{1} \mathrm{HNMR}$ spectra were recorded in $\mathrm{CDCl}_{3}$ and $\mathrm{DMSO}-\mathrm{d} 6$ using a $400 \mathrm{MHz}$ instrument. ${ }^{13} \mathrm{C}$ NMR spectra were recorded in $\mathrm{CDCl}_{3}$ and DMSO-d6 using a $400 \mathrm{MHz}$ instrument. Signals due to the solvent $\left({ }^{13} \mathrm{C}\right.$ NMR) or residual protonated solvent $\left({ }^{1} \mathrm{H}\right.$ NMR $)$ served as the internal standard. The ${ }^{1} \mathrm{H}$ NMR chemical shifts and coupling constants were determined assuming first-order behavior. Multiplicity is indicated by one or more of the following: s (singlet), $\mathrm{d}$ (doublet), $\mathrm{t}$ (triplet), $\mathrm{q}$ (quartet), $\mathrm{m}$ (multiplet), br (broad); the list of coupling constants $(\mathrm{J})$ corresponds to the order of multiplicity assignment. TLC analyses were performed on silica gel precoated-plates $(250 \mu \mathrm{m}$ layers $)$. We note that our stereo chemical assignments are supported by comparisons with the literature. HPLC analysis was performed with Waters Symmetry shield RP18 $(250 X 4.6 \mathrm{~mm}, 5 \mu)$ column by using gradient elution and monitored at $220 \mathrm{~nm}$.

(R)-Ethyl 2-(2-((tert-butoxycarbonyl)amino)-3-(1H-indol-3-yl)- $N$-methyl propanamido) acetate (11). A mixture of $N$-Boc-D-tryptophan $(5 \mathrm{~g}, 16.4 \mathrm{mmol})$ and THF $(25 \mathrm{~mL})$ was cooled to $-20{ }^{\circ} \mathrm{C}$ under nitrogen atmosphere. To the mixture charged $N$-methyl morpholine $(1.83 \mathrm{~g}, 18$ $\mathrm{mmol})$ and stirred for $20 \mathrm{~min}$. Thereafter, a solution of ethyl chloroformate $(1.95 \mathrm{~g}, 18 \mathrm{mmol})$ in THF ( $2 \mathrm{~mL}$ ) was slowly added and stirred the reaction mass for $30 \mathrm{~min}$. Subsequently, a solution of sarcosine ethyl ester in THF $(5 \mathrm{~mL})$ was prepared by treating sarcosine ethyl ester hydrochloride ( $2.76 \mathrm{~g}, 18 \mathrm{mmol}$ ) with $\mathrm{N}$-methyl morpholine ( $2 \mathrm{~g}$ ). This solution was added to the solution of mixed anhydride in THF drop wise at $-20{ }^{\circ} \mathrm{C}$. The reaction mass was allowed to attain ambient temperature and maintained for $1 \mathrm{~h}$. After completion of the reaction, solvent was removed by distillation (CAUTION: THF forms peroxides while distillation and hence PPE should be wear during concentration of THF) and to the obtained residue water and DCM were charged. After stirring, organic layer was separated and $2 \mathrm{~N} \mathrm{HCl}$ washings $(2 \mathrm{x} 10 \mathrm{~mL})$ were given followed by bicarbonate washing $(1 \times 10 \mathrm{~mL})$. The organic layer was evaporated to give compound 11 in $5.4 \mathrm{~g}, 81 \%$ yield; mp $126-128{ }^{\circ} \mathrm{C} ;{ }^{1} \mathrm{H}$ NMR $\left(400 \mathrm{MHz}, \mathrm{CDCl}_{3}\right) \delta 1.27$ (t, 3H, $J$ $7.2 \mathrm{~Hz}), 1.42$ (s, 9H), $2.77(\mathrm{~s}, 3 \mathrm{H}), 3.13-3.24(\mathrm{~m}, 2 \mathrm{H}), 3.9-4.08(\mathrm{~m}, 2 \mathrm{H}), 4.17$ (q, 2H, J 7.2 Hz), $4.99(\mathrm{dd}, 1 \mathrm{H}, J 7.8 \mathrm{~Hz}), 5.41-5.43(\mathrm{~d}, 1 \mathrm{H}), 7.1-7.35(\mathrm{~m}, 4 \mathrm{H}), 7.6(\mathrm{~d}, 1 \mathrm{H}, J 7.8 \mathrm{~Hz}), 8.11$ (br s, $1 \mathrm{H}) ;{ }^{13} \mathrm{C}$ NMR $\left(100 \mathrm{MHz}, \mathrm{CDCl}_{3}\right) \delta 14.2,24.9,25.6,28.3,29.3,33.9,36.2,49.6,50.8,51.0$, $61.2,77.6,110.2,111.1,118.7,119.5,121.9,123.3,136.0,155.2,168.9,172.8$; IR (KBr) v 3295, 3060, 2981, 2933, 1750, 1688, 1645, 1459, 1203, 1171, $746 \mathrm{~cm}^{-1} ;[\alpha]_{\mathrm{D}}^{28.4}-4.65$ (c 0.50 , $\mathrm{CH}_{3} \mathrm{OH}$ ); HRMS (ESI) calcd for $\mathrm{C}_{21} \mathrm{H}_{30} \mathrm{~N}_{3} \mathrm{O}_{5}\left[\mathrm{M}^{+}+\mathrm{H}\right]$ : 404.2185 ; Found: 404.2171.

$(6 R, 12 \mathrm{a} R)-6-(B e n z o[d][1,3]$ dioxol-5-yl)-2-methyl-2,3,12,12a-tetrahydropyrazino[1',2':1,6] pyrido[3,4-b]indole-1,4(6H,7H)-dione $(1 \mathrm{c})$. A mixture of toluene $(10 \mathrm{~mL})$, compound $11(1 \mathrm{~g}$, 
$12.4 \mathrm{mmol})$ and compound $2(0.36 \mathrm{~g}, 12.65 \mathrm{mmol})$ were stirred for $10 \mathrm{~min}$. Trifluoroacetic acid was added slowly and the reaction mass was heated to $45-50{ }^{\circ} \mathrm{C}$, maintained at the same temperature for $15 \mathrm{~h}$ and concentrated under vacuum. To the obtained residue, charged water (5 $\mathrm{mL})$ and dichloromethane $(5 \mathrm{~mL})$ and the mixture was neutralized with saturated sodium bicarbonate solution. Organic layer was separated and concentrated below $35^{\circ} \mathrm{C}$ under vacuum. Charged toluene $(5 \mathrm{~mL})$ to the obtained residue and the mixture was heated to reflux. After stirring for $8 \mathrm{~h}$, reaction mass was cooled to ambient temperature and the product separated was filtered to give tadalafil, $1 \mathrm{c}$ in $0.39 \mathrm{~g}, 50 \%$ yield; mp $301-303{ }^{\circ} \mathrm{C}$; purity by HPLC $99.9 \%$; ${ }^{1} \mathrm{H}$ NMR (400 MHz, $\left.\mathrm{CDCl}_{3}\right) \delta 3.04$ (s, 3H), 3.18-3.25 (m, 1H), 3.77 (dd, 1H, J 4.4Hz, 16.1Hz), 3.93 $(\mathrm{d}, 1 \mathrm{H}, J 17.7 \mathrm{~Hz}), 4.08(\mathrm{~d}, 1 \mathrm{H}, J 17.7 \mathrm{~Hz}), 4.29-4.31(\mathrm{~m}, 1 \mathrm{H}), 5.85(\mathrm{~s}, 2 \mathrm{H}), 6.15(\mathrm{~s}, 1 \mathrm{H}), 6.67-$ $6.73(\mathrm{~m}, 2 \mathrm{H}), 6.84-6.86(\mathrm{~m}, 1 \mathrm{H}), 7.14-7.18(\mathrm{~m}, 2 \mathrm{H}), 7.26-7.28(\mathrm{~m}, 1 \mathrm{H}), 7.61(\mathrm{~d}, 1 \mathrm{H}, J 6.4), 7.9$ (s, $1 \mathrm{H}) ;{ }^{13} \mathrm{C}$ NMR $\left(100 \mathrm{MHz}, \mathrm{CDCl}_{3}\right) \delta 23.8,33.6,52.1,56.2,56.6,101.1,106.4,107.4,108.2$, $111.2,118.6,120.0,120.6,122.4,126.1,132.8,135.3,136.5,147.1,147.8,166.4,166.8$; IR $(\mathrm{KBr})$ v 3327, 3061, 2904, 1677, 1650, 1627, 1438, 1323, 1242, 1041, 939, 922, $746 \mathrm{~cm}^{-1}$; $[\alpha]_{\mathrm{D}}^{26.8} 70.54$ (c $0.99, \mathrm{CHCl}_{3}$ ); HRMS calcd for $\mathrm{C}_{22} \mathrm{H}_{20} \mathrm{~N}_{3} \mathrm{O}_{4}\left[\mathrm{M}^{+}+\mathrm{H}\right]:$ 390.1454; Found: 390.1454 .

(R)-3-((1H-Indol-3-yl)methyl)-1-methyl piperazine-2, 5-dione (15). Method a. A mixture of compound $11(2 \mathrm{~g}, 12.4 \mathrm{mmol})$ and hydrochloric acid in dioxane $(20 \mathrm{~mL}, 4 \mathrm{~N})$ and stirred at ambient temperature for $5 \mathrm{~h}$. Thereafter, reaction mass was concentrated under reduced pressure. Charged DCM and washed with saturated sodium bicarbonate solution (15 mL). Then, solvent was evaporated under reduced pressure to get the desired compound $\mathbf{1 5}$ in $0.9 \mathrm{~g}, 70 \%$ yield. Method b. A suspension of $\mathrm{HCl}$ salt of compound $3(1.17 \mathrm{~g}, 4.58 \mathrm{mmol})$ in chloroform (10 mL), to that added aqueous ammonia solution $(2 \mathrm{~mL})$ and water $(10 \mathrm{~mL})$ and stirred at ambient temperature for $10 \mathrm{~min}$. Organic layer was separated and solvent was evaporated under reduced pressure. The obtained residue was diluted with chloroform $(10 \mathrm{~mL})$ then added triethyl amine $(0.394 \mathrm{~g}, 3.894 \mathrm{mmol})$ and cooled to $0{ }^{\circ} \mathrm{C}$. Compound $5(0.66 \mathrm{~g}, 5.84 \mathrm{mmol})$ was added and the reaction mass was stirred for $1 \mathrm{~h}$. Thereafter, water $(10 \mathrm{~mL})$ was added to the mass below $10{ }^{\circ} \mathrm{C}$, and organic layer was separated and washed with saturated sodium bicarbonate solution followed by water. Finally, organic layer was distilled under vacuum. To the obtained compound, methylamine $(0.42 \mathrm{~g}, 13.548 \mathrm{mmol})$ in methanol $(10 \mathrm{~mL})$ was added and stirred for $6 \mathrm{~h}$ at $55^{\circ} \mathrm{C}$ for completion of the reaction. Subsequently, the reaction mass was cooled to ambient temperature and separated solids were filtered. The filtrate was evaporated to get the desired compound 15 in $0.95 \mathrm{~g}, 80 \%$ yield; mp $234-236{ }^{\circ} \mathrm{C}$; ${ }^{1} \mathrm{H}$ NMR (400 MHz, DMSO-d 6 ) $\delta 2.46$ (s, 3H), 2.98 (dd, 1H, J 4.4 Hz, 14.4 Hz), 3.27 (dd, 1H, J $3.9 \mathrm{~Hz}, 14.4 \mathrm{~Hz}), 3.36$ (s, 3H), 4.1 (br s, 1H), 6.9-7.1 (m, 3H), 7.34 (d, 1H, J 7.9 Hz), 7.43 (d, 1H, J 7.9 Hz) 8.18 (br s, 1H, NH), 11.0 (br $\mathrm{s}, 1 \mathrm{H}) ;{ }^{13} \mathrm{C}$ NMR $\left(100 \mathrm{MHz}, \mathrm{DMSO}-\mathrm{d}_{6}\right), \delta 30.1,32.8,50.4,55.5,107.9,111.3,118.3,118.7$, 121.0, 125.0, 127.2, 136.0, 165.1, 166.3; IR (KBr) v 3250, 3057, 2931, 1686, 1650, 1630, 1474, 1321, 1189, 1103, 1028, 738, $712 \mathrm{~cm}^{-1} ;[\alpha]_{\mathrm{D}}^{28.4}-133.5\left(\mathrm{c} 0.49, \mathrm{CH}_{3} \mathrm{OH}\right) ;$ HRMS calcd. for $\mathrm{C}_{14} \mathrm{H}_{16} \mathrm{~N}_{3} \mathrm{O}_{2}\left(\mathrm{M}^{+}+\mathrm{H}\right)$ 258.1243; found $\left(\mathrm{M}^{+}+\mathrm{H}\right) 258.1246$. 
$(6 S, 12 \mathrm{a} R)-6-(B e n z o[d][1,3]$ dioxol-5-yl)-2-methyl-2,3,12,12a-tetrahydropyrazino[1',2':1,6] pyrido[3,4-b]indole-1,4(6H,7H)-dione (12). Method a. A mixture of toluene (10 $\mathrm{mL})$, compound 11 ( $1 \mathrm{~g}, 12.4 \mathrm{mmol})$ and compound $2(0.36 \mathrm{~g}, 12.65 \mathrm{mmol})$ was stirred for $10 \mathrm{~min}$. Trifluoroacetic acid was added slowly and the reaction mass was heated to reflux and maintained at the same temperature for $8 \mathrm{~h}$. Thereafter, the reaction mass was cooled to ambient temperature and neutralize it with saturated sodium bicarbonate solution. Charge dichloromethane $(15 \mathrm{~mL})$ to the mass and stir for $10 \mathrm{~min}$. Organic layer was separated and concentrated below $35{ }^{\circ} \mathrm{C}$ under vacuum and the product was purified by column chromatography to give pure $S, R$ isomer of tadalafil, 12 in $0.7 \mathrm{~g}, 65 \%$ yield. Method b. A mixture of compound 15 (2 g, $7.78 \mathrm{mmol})$ and 2 $(1.17 \mathrm{~g}, 7.78 \mathrm{mmol})$ is taken along with aqueous $\mathrm{HCl}(10 \mathrm{~mL}, 6 \mathrm{~N})$ and dioxane $(10 \mathrm{~mL})$ and stirred at reflux temperature for $1 \mathrm{~h}$. Thereafter, reaction mass was concentrated under reduced pressure. Charged DCM and washed with saturated sodium bicarbonate solution $(30 \mathrm{~mL})$. Subsequently, solvent was evaporated under reduced pressure followed by purification through column chromatography using petroleum ethers: ethyl acetate (7:3) to give pure compound $\mathbf{1 2}$ in $2.4 \mathrm{~g}, 80 \%$ yield; mp $287-288{ }^{\circ} \mathrm{C}$; purity by HPLC $99.0 \% ;{ }^{1} \mathrm{H}$ NMR $\left(400 \mathrm{MHz}, \mathrm{CDCl}_{3}\right) \delta 2.91$ $2.98(\mathrm{~m}, 1 \mathrm{H}), 3.0(\mathrm{~s}, 3 \mathrm{H}), 3.55(\mathrm{dd}, 1 \mathrm{H}, J 12 \mathrm{~Hz}, 4.4 \mathrm{~Hz}), 4.0(\mathrm{~s}, 2 \mathrm{H}, J 17.7 \mathrm{~Hz}), 4.14$ (d, 2H, $J$ $17.6 \mathrm{~Hz}), 4.35(\mathrm{dd}, 1 \mathrm{H}, J 11.9 \mathrm{~Hz}, 4.4 \mathrm{~Hz}), 5.9$ (s, 2H), $6.72(\mathrm{~s}, 2 \mathrm{H}), 6.82$ (s, 1H, Ar), 6.98 (s, 1H), 7.14-7.24 (m, 2H), $7.28(\mathrm{~d}, 1 \mathrm{H}, J 7.8 \mathrm{~Hz}), 7.53(\mathrm{~d}, 1 \mathrm{H}, J 7.8 \mathrm{~Hz}), 7.90(\mathrm{br} \mathrm{s}, 1 \mathrm{H}) ;{ }^{13} \mathrm{C} \mathrm{NMR}$ $\left(100 \mathrm{MHz}, \mathrm{CDCl}_{3}\right), \delta$ 27.6, 33.4, 51.4, 51.8, 52.4, 101.3, 108.3, 109.0, 119.1, 111.1, 118.4, 120.0, 122.4, 122.7, 126.2, 129.7, 132.3, 136.3, 148.0, 148.1, 161.5, 165.4; IR (KBr) v 3348, $3060,2926,1657,1623,1594,1452,1325,1263,1040,934.9,746.1 \mathrm{~cm}^{-1} ;[\alpha]_{\mathrm{D}}{ }^{28} 278(\mathrm{c} 1.03$, $\mathrm{CHCl}_{3}$ ); HRMS calcd for $\mathrm{C}_{22} \mathrm{H}_{20} \mathrm{~N}_{3} \mathrm{O}_{4}\left[\mathrm{M}^{+}+\mathrm{H}\right]: 390.1454$. Found: 390.1460 .

Procedure for preparation of compounds 17. A mixture of compound $\mathbf{1 5}(7.78 \mathrm{mmol})$ and 16 $(7.78 \mathrm{mmol})$ in aqueous $\mathrm{HCl}(10 \mathrm{~mL}, 6 \mathrm{~N})$ and dioxane $(10 \mathrm{~mL})$ is stirred at reflux temperature. After stirring for $1 \mathrm{~h}$, reaction mass was concentrated under reduced pressure and DCM was charged and washed with saturated sodium bicarbonate solution $(30 \mathrm{~mL})$. Theraafter, solvent was evaporated under reduced pressure to get crude compound $\mathbf{1 7}$ followed by its purification through column chromatography using petroleum ethers: ethylacetate (7:3) to give pure compound $\mathbf{1 7}$ in $80-85 \%$ yield range.

(6S,12aR)-6-(2-Bromophenyl)-2-methyl-2,3,12,12a-tetrahydropyrazino[1',2':1,6]pyrido[3,4b]indole-1,4(6H,7H)-dione (17a). 80\% Isolated yield; mp 283-284 ${ }^{\circ} \mathrm{C}$; purity by HPLC 99.9\%; ${ }^{1} \mathrm{H}$ NMR (400 MHz, $\mathrm{CDCl}_{3}$ ) $\delta$ 2.92-2.96 (m, 1H), 3.02 (s, 3H), 3.49 (dd, 1H, J $15.6 \mathrm{~Hz}, 4.3 \mathrm{~Hz}$ ), 4.07-4.13 (m, 2H), $4.33(\mathrm{dd}, 1 \mathrm{H}, J 11.95 \mathrm{~Hz}, 4.4 \mathrm{~Hz}), 6.84(\mathrm{~d}, 1 \mathrm{H}, J 9.3 \mathrm{~Hz}), 7.16-7.26(\mathrm{~m}, 5 \mathrm{H})$, $7.32(\mathrm{~d}, 1 \mathrm{H}, J 7.8 \mathrm{~Hz}), 7.52(\mathrm{~d}, 1 \mathrm{H}, J 7.8 \mathrm{~Hz}), 7.65$ (d, 1H, J 9.3 Hz), 7.97 (br s, 1H); ${ }^{13} \mathrm{C} \mathrm{NMR}$ $\left(100 \mathrm{MHz}, \mathrm{CDCl}_{3}\right) \delta 14.1,27.3,29.7,33.3,51.4,52.2,53.0,60.4,108.7,111.3,118.3,120.0$, $122.7,124.1,126.2,127.5,129.8,130.3,131.1,133.7,136.3,136.7,163.2,166.1$; IR (KBr) $v$ $3305,3057,2930,1668,1655,1621,1453,1328,1041,743.5 \mathrm{~cm}^{-1} ;[\alpha]_{\mathrm{D}}^{29.6} 199.78(\mathrm{c} 0.50$, $\left.\mathrm{CHCl}_{3}\right)$; EI-MS m/z $422\left[\mathrm{M}^{-}\right]$.

$(6 S, 12 \mathrm{a} R)$-6-(4-Methoxyphenyl)-2-methyl-2,3,12,12a-tetrahydropyrazino[1',2':1,6]pyrido$[3,4-b]$ indole-1,4(6H,7H)-dione (17b). $82 \%$ Isolated yield; mp 245-246 ${ }^{\circ} \mathrm{C}$; purity by HPLC 
99.0\%; ${ }^{1} \mathrm{H}$ NMR (400 MHz, $\left.\mathrm{CDCl}_{3}\right) \delta$ 2.92-2.96 (m, 1H), $2.99(\mathrm{~s}, 3 \mathrm{H}), 3.56(\mathrm{dd}, 1 \mathrm{H}, J 15.5 \mathrm{~Hz}$, $4.4 \mathrm{~Hz}$ ), 3.8 (s, 3H), 3.99 (d, 1H, J 17.6 Hz), 4.1 (d, 1H, J 17.6 Hz), 4.34 (dd, 1H, J $11.95 \mathrm{~Hz}, 4.4$ $\mathrm{Hz}), 6.84(\mathrm{~m}, 2 \mathrm{H}), 7.0(\mathrm{~s}, 1 \mathrm{H}), 7.16-7.23(\mathrm{~m}, 4 \mathrm{H}), 7.31(\mathrm{~d}, 1 \mathrm{H}, J 7.8 \mathrm{~Hz}), 7.52(\mathrm{~d}, 1 \mathrm{H}, J 7.6 \mathrm{~Hz})$, 7.86 (brs, $1 \mathrm{H}) ;{ }^{13} \mathrm{C}$ NMR $\left(100 \mathrm{MHz}, \mathrm{CDCl}_{3}\right) \delta 27.6,33.3,51.3,51.5,52.3,55.3,108.7,111.1$, $114.1,118.3,119.8,122.5,126.2,130.0,130.5,136.3,159.8,161.4,165.4$; IR (KBr) v 3333, $3057,2932,1658,1648,1591,1459,1329,1237,1126,1004,745,708 \mathrm{~cm}^{-1} ;[\alpha]_{\mathrm{D}}^{29.4} 202.63(\mathrm{c}$ $\left.0.49, \mathrm{CHCl}_{3}\right)$; EI-MS m/z $374\left[\mathrm{M}^{-}\right]$.

$(6 S, 12 \mathrm{a} R)$-2-Methyl-6-(3,4,5-trimethoxyphenyl)-2,3,12,12a-tetrahydropyrazino[1',2':1,6]pyrido[3,4-b]indole-1,4(6H,7H)-dione (17c). 85\% Isolated yield; mp 239-240 ${ }^{\circ} \mathrm{C}$; purity by HPLC 99.5\%; ${ }^{1} \mathrm{H}$ NMR (400 MHz, $\left.\mathrm{CDCl}_{3}\right) \delta$ 2.93-2.98 (m, 1H), $3.08(\mathrm{~s}, 3 \mathrm{H}), 3.58(\mathrm{dd}, 1 \mathrm{H}, J$ $15.6 \mathrm{~Hz}, 4.4 \mathrm{~Hz}$ ), 3.7 (s, 3H), 3.8 (s, 6H), 4.01 (d, 1H, J 17.6 Hz), 4.15 (d, 1H, J $17.6 \mathrm{~Hz}), 4.4$ (dd, 1H, J 12.2 Hz, 3.9 Hz,), 6.51 (s, 2H), $6.98(\mathrm{~s}, 1 \mathrm{H}), 7.15-7.26(\mathrm{~m}, 2 \mathrm{H}), 7.33$ (d, 1H, J 7.9 Hz), $7.55(\mathrm{~d}, 1 \mathrm{H}, J 7.9 \mathrm{~Hz}), 8.03$ (br s, $1 \mathrm{H}) .{ }^{13} \mathrm{C} \mathrm{NMR}\left(100 \mathrm{MHz}, \mathrm{CDCl}_{3}\right) \delta$ 27.6, 33.3, 51.3, 52.3, 52.8, 55.9, 60.5, 105.5, 108.5, 111.2, 118.2, 119.5, 122.3, 126.0, 134.1, 136.4, 137.4, 152.9, 161.5, 165.5; IR (KBr) v 3266, 3058, 2925, 1655, 1464, 1329, 1248, 1175, 1158, $744 \mathrm{~cm}^{-1}$ $[\alpha]_{\mathrm{D}}^{29.4}: 220.19\left(\mathrm{c} 0.50, \mathrm{CHCl}_{3}\right) ; \mathrm{EI}-\mathrm{MS} \mathrm{m} / z 434\left[\mathrm{M}^{-}\right]$.

\section{Acknowledgements}

We thank the management of Dr. Reddy's Laboratories Ltd. for supporting the work. Dr. Reddy's communication number IPDO IPM-00298.

\section{References}

1. Airaksinen, M. M.; Kari, I. Med. Biol. 1981, 59, 21.

2. Cox, E. D.; Cook, J. M. Chem. Rev. 1995, 95, 1797.

3. Daugan, A.; Grondin, P.; Ruault, C.; Le Monnier de Gouville, A. C.; Coste, H.; Kirilovsky, J.; Hyafil, F.; Labaudinière, R. J. Med. Chem. 2003, 46, 4525.

4. Pictet, A.; Spengler, T. Ber. Dtsch. Chem. Ges. 1911, 44, 2030.

5. Tatsui, G. Yakugaku Zasshi 1928, 48, 453.

6. Tepe, J. J.; Madalengoitia, J. S.; Slunt, K. M.; Werbovetz, K. A.; Spoors, P. G.; Macdonald, T. L. J. Med. Chem. 1996, 39, 2188-2196.

7. Liao, X.; Zhou, H.; Yu, J.; Cook, J. M. J. Org. Chem. 2006, 71, 8884.

8. Zhang, L. H.; Cook, J. M. J. Am. Chem. Soc. 1990, 112, 4088.

9. Mohamed, H. A.; Girgis, N. M. R.; Wilcken, R.; Bauer, M. R.; Tinsley, H. N.; Gary, B. D.; Piazza, G. A.; Boeckler, F. M.; Abadi, A. H. J. Med. Chem. 2011, 54, 495.

10. Brahmbhatt, K. G.; Ahmed, N.; Sabde, S.; Mitra, D.; Singh, I.P.; Bhutani, K. K. Bioorg. Med. Chem. Lett. 2010, 20, 4416. 
11. Sorbera, L. A.; Martin, L.; Leeson, P. A.; Castaner, J. Drugs Fut. 2001, 26, 15.

12. Daugan, A.; Grondin, P.; Ruault, C.; Le Monnier de Gouville, A. C.; Coste, H.; Linget, J.M.; Kirilovsky, J.; Hyafil, F.; Labaudinière, R. J. Med. Chem. 2003, 46, 4533.

13. Orme, M. W.; Martinelli, M. J.; Doecke, C. W.; Pawlak, J. M. World Patent, WO 04/011463, 2004.

14. Xiao, S.; Shi, X.-X.; Ni, F.; Xing, J.; Yan, J.-J.; Liu, S.-L.; Lu, W.-D. Tetrahedron: Asymm. 2009, 20, 2090.

15. Raghupathi Reddy, A.; Lokeswara Rao, M.; Goverdhan, G.; Prasad Raju, V. V. N. K.V.; Mukkanti, K.; Pratap Reddy, P.; Apurba, B.; Rakeshwar, B. Syn. Comm. 2008, 38, 4265.

16. Shi, X.-X.; Liu, S.-L.; Xu, W.; Xu, Y.-L. Tetrahedron: Asymm. 2008, 19, 435.

17. Czerwinski, K. M.; Deng, L.; Cook, J. M. Tetrahedron. Lett. 1992, 33, 4721.

18. Xiao, S.; Shi, X.-X.; Ni, F.; Xing, J.; Yan, J.-J.; Liu, S.-L. Eur. J. Org. Chem. 2010, 9, 1711.

19. Ungemach, F.; DiPierro, M.; Weber, R.; Cook, J. M. J. Org. Chem. 1981, 46, 164.

20. Dunn, P. J. Org. Pro. Res. Dev. 2005, 9, 88.

21. Rhoden, C. R. B.; Rivera, D. G.; Kreye, O.; Bauer, A. K.; Westermann, B.; Wessjohann, L. A. J. Comb. Chem. 2009, 11, 1078.

22. Pulka, K.; Kulis, P.; Tymecka, D.; Frankiewicz, L.; Wilczek, M.; Kozminski, W.; Misicka, A. Tetrahedron 2008, 64, 1506.

23. Madalengoitia, J. S.; Tepe, J. J.; Werbovetz, K. A.; Lehnert, E. K.; Macdonald, T. L. Bioorg. Med. Chem. 1997, 5, 1807. 